\title{
Too many digits: the presentation of numerical data
}

T J Cole

Emperor Joseph II: My dear young man, don't take it too hard. Your work is ingenious. It's quality work. And there are simply too many notes, that's all. Just cut a few and it will be perfect.

Mozart: Which few did you have in mind, Majesty?

Emperor Joseph II: Well, there it is.

Quotation from the film Amadeus (1984)

As a statistical reviewer for Archives and $B M J$ I am interested in the presentation of numerical data. ${ }^{1}$ It concerns me that numbers are often reported to excessive precision, because too many digits can swamp the reader, overcomplicate the story and obscure the message.

A number's precision relates to its decimal places or significant figures (or as preferred here, significant digits). The number of decimal places is the number of digits to the right of the decimal point, while the number of significant digits is the number of all digits ignoring the decimal point, and ignoring all leading zeros and some trailing zeros (for a fuller definition see 'significant figures' on Wikipedia).

Ideally data should be rounded appropriately, not too much and not too little (one might call it Goldilocks rounding). ${ }^{2}$ The European Association of Science Editors guidelines include the useful rule of thumb: "numbers should be given in (sic) 2-3 effective digits". ${ }^{3}$

Take as an example the odds ratio (OR) of 22.68 (95\% CI 7.51 to 73.67 ) comparing beta mimetics with placebo for side effects requiring a change of medication. ${ }^{4}$ Its two decimal places and four significant digits are excessive when the effect size and confidence interval (CI) are so large. Reporting it rounded to two significant digits, as 23 (7.5 to 74 ), or even as 23 (8 to 70 ), with one significant digit for the CI, would be simpler and clearer.

There are several published recommendations (or reporting rules) about rounding numbers, some of which relate to decimal places (eg, the Cochrane Style Guide $^{5}$ or APA Style ${ }^{6}$ to round to two

Correspondence to Professor T I Cole, Population, Policy and Practice Programme, UCL Institute of Child Health, London WC1N 1EH, UK; tim.cole@ucl.ac.uk decimal places), some to significant digits (eg, the European Association of Science Editors guideline above ${ }^{3}$ ) and some to a combination of the two (eg, setting the number of decimal places to ensure two significant digits for the standard deviation $\left.(\mathrm{SD})^{7}\right)$. However, the message here is that rules of the first type, specifying the number of decimal places and ignoring the number of significant digits, are inherently unsatisfactory, as the following examples show.

Birth weight is usually reported in units of grams, for example, "birth weight ... resulting from blastocyst transfer was significantly greater than ... resulting from Day 3 transfer $(3465.31 \pm 51.36 \mathrm{~g}$ vs $3319.82 \pm 10.04 \mathrm{~g}$ respectively, $\mathrm{p}=0.009)$ ). ${ }^{8}$ However it is also reported in kilograms: "The mean birth weight of babies was $3.05 \pm 0.57$ (95\% CI 2.95 to 3.15 ) kg”. In both articles birth weight is reported to two decimal places, but due to the different units they correspond to six and three significant digits, respectively. The first is clearly excessive while the second is about right, giving the SD to two significant digits. ${ }^{7}$ By analogy, birth weight in grams ought to be rounded to the nearest $10 \mathrm{~g}$.

A second example is the Cochrane Style Guide, which requires risk ratios to be reported to two decimal places. ${ }^{5}$ This is clearly unsatisfactory for ratios that are very large (see the example above) or very small, for example a hazard ratio (HR) of 0.03 (95\% CI 0.01 to 0.05 ) for the updating of systematic review citations in Clinical Evidence versus Dynamed. ${ }^{10}$ If the direction of the HR were reversed its true value could be anywhere between 29 and 40 due to the extreme rounding.

As a third example, $p$ values, it has been suggested, should be rounded to one or two decimal places. ${ }^{2}$ For $\mathrm{p}$ values above the conventional 0.05 cut-off there is little justification for quoting more than one decimal place, while for significant results three or even four decimals may be necessary. The better rule is to report rounded up to one significant digit, which works across the spectrum of values. ${ }^{1}$

Thus a decimal places rule that ignores significant digits does not work. But equally, and perhaps surprisingly, a significant digits rule that ignores decimal places does not always work either. Reporting risk ratios to three significant digits for example leads to the largest ratio below 1 being reported as 0.999 and the smallest above 1 as 1.01, with three and two decimal places, respectively. This is clearly unsatisfactory as they differ in precision by a factor of ten. In this instance a combination of significant digits and decimal places, the rule of four, ${ }^{11}$ works best: round the risk ratio to two significant digits if the leading non-zero digit is four or more, otherwise round to three.

The rule of four gives three decimal places for risk ratios from 0.040 to 0.399 , two from 0.40 to 3.99 and one from 4.0 to $39.9 .^{11}$ Applying it to the example of 22.68 above gives 22.7 (95\% CI 7.5 to 74). Alternatively one can apply the rule with one less significant digit, giving 23 with CI 8 to $70 .^{11}$

Another example is the reporting of test statistics such as $t$ or $F$. Specifying one decimal place would permit say $\mathrm{t}=30.1$, where 30 is clearly sufficient as it is so highly significant. Conversely specifying two significant digits would permit $\mathrm{t}=-0.13$, where again the extra precision is irrelevant as it is far from significant. A suitable rule specifies up to one decimal place and up to two significant digits.

When comparing group means or percentages in tables, rounding should not blur the differences between them. This is the basis for the Hopkins two digits rule, ${ }^{7}$ whereby the mean has enough decimal places to ensure two significant digits for the SD. An analogous rule for percentages might be to use enough decimal places to ensure two significant digits for the range of values across groups, eg, if the range is $10 \%$ or more use whole numbers, if less than $1 \%$ use two decimal places, and otherwise one. In practice percentages are usually given along with their corresponding frequencies, so precision is less critical as the exact values can be calculated.

Recognising the fallibility of decimal places rules means that tables ought not to be restricted to columns of numbers with fixed decimal places, and this adds flexibility when deciding how many decimals to use. For example measures of variability, eg, standard errors (SE)s or CIs, need not be as precise as the effect size, particularly if the CI is wide. A useful trick when formatting table columns is to align the numbers by decimal point, which highlights differences in the number of decimal places. This is particularly useful in columns of risk ratios or $\mathrm{p}$ values-see the examples in the table.

It is important that any intermediate calculations are carried out to full 
Table 1 Rounding rules for summary statistics

\begin{tabular}{|c|c|c|}
\hline $\begin{array}{l}\text { Summary } \\
\text { statistic }\end{array}$ & Reporting & $\begin{array}{l}\text { Examples } \\
\text { (where useful) }\end{array}$ \\
\hline Mean & $\begin{array}{l}\text { Use enough decimal places to give either the SD to two significant digits, } \\
\text { or the SE to one significant digit }\end{array}$ & $\begin{array}{l}3320 \mathrm{~g} \\
3.32 \mathrm{~kg}\end{array}$ \\
\hline Percentage & $\begin{array}{l}\text { Integers, or one decimal place for values under } 10 \% \text {. Values over } 90 \% \text { may } \\
\text { need one decimal place if their complement is informative. Use two or } \\
\text { more decimal places only if the range of values is less than } 0.1 \%\end{array}$ & $\begin{array}{l}0.1 \% \\
5.3 \% \\
27 \% \\
89 \% \\
99.6 \%\end{array}$ \\
\hline $\begin{array}{l}\text { Mean } \\
\text { difference }\end{array}$ & $\begin{array}{l}\text { Use enough decimal places to give the SE to one or two significant digits. } \\
\text { For a standardised mean difference use one or two decimal places }\end{array}$ & \\
\hline $\begin{array}{l}\text { Regression } \\
\text { coefficient }\end{array}$ & As with the mean difference. & \\
\hline $\begin{array}{l}\text { Correlation } \\
\text { coefficient }\end{array}$ & One or two decimal places, or more when very close to \pm 1 & $\begin{array}{l}0.03 \\
-0.7 \\
0.89 \\
0.999\end{array}$ \\
\hline Risk ratio & $\begin{array}{l}\text { Round to two significant digits if the leading non-zero digit is four or more, } \\
\text { otherwise round to three (the rule of four }{ }^{11} \text { ). Alternatively use one/two } \\
\text { significant digits rather than two/three. For ORs very close to } 1 \text { (eg, in } \\
\text { logistic regression with a continuous variable) use three decimal places or } \\
\text { else report the log } 0 R \times 100 \text { as the percentage odds to one decimal place }{ }^{13}\end{array}$ & $\begin{array}{l}0.0321 \\
0.062 \\
0.76 \\
1.05 \\
4.2 \\
11.3 \\
55 \\
1.042 \\
4.1 \%\end{array}$ \\
\hline SD & One or two significant digits ${ }^{7}$ & $\begin{array}{l}570 \mathrm{~g} \\
0.57 \mathrm{~kg} \\
9 \mathrm{~mm} \mathrm{Hg} \\
2.5 \mathrm{~mL}\end{array}$ \\
\hline SE & One or two significant digits & \\
\hline $\mathrm{Cl}$ & $\begin{array}{l}\text { Use the same rule as for the corresponding effect size (be it mean, } \\
\text { percentage, mean difference, regression coefficient, correlation coefficient } \\
\text { or risk ratio), perhaps with one less significant digit }\end{array}$ & \\
\hline $\begin{array}{l}\text { Test statistics: } \\
\mathrm{t}, \mathrm{F}, \chi^{2} \text {, etc }\end{array}$ & Up to one decimal place and up to two significant digits & $\begin{array}{l}\mathrm{t}=-1.3 \\
\mathrm{~F}=11 \\
\chi^{\mathrm{s}}=4.1\end{array}$ \\
\hline$p$ value & $\begin{array}{l}\text { Round up to one significant digit, within the limits shown in the examples. } \\
\text { The lower limit may be smaller than } 0.001 \text {, but never } 0.000 \text {. For } \\
\text { genome-wide association studies use the power of } 10 \text { format }\end{array}$ & $\begin{array}{c}>0.9 \\
0.4 \\
0.1 \\
0.08 \\
0.05 \\
0.003 \\
<0.001 \\
6.10^{-9}\end{array}$ \\
\hline
\end{tabular}

precision, and that rounding is done only at the reporting stage. This raises the question as to whether the rounded results need extra precision in case they are later included in meta-analyses. But to my mind this confuses two distinct aimsto present the results as accessibly as possible, and to report the results as raw data for meta-analysis. If the two aims are mutually exclusive then the first has to take priority. But in practice they may not be mutually exclusive-where effect sizes are rounded to two or three significant digits the rounding error variance is likely to be small compared with the inter-study variance, making the rounding imprecision relatively unimportant.

Table 1 gives an evidence-based set of recommendations for rounding the types of summary statistic that arise commonly in medical scientific writing. The general principle is to use two or three significant digits for effect sizes, and one or two significant digits for measures of variability. $^{3} 12$ However, optimal precision, like beauty, is in the eye of the beholder, and they should be recognised as recommendations not requirements. Their main purpose is to address the pervasive problem of reporting too many digits.

Fortunately for us, Emperor Joseph did not tell Mozart which notes he should cut, but here researchers have a clear steer as to which digits they can ditch.

\section{Competing interests None.}

Provenance and peer review Commissioned; internally peer reviewed.

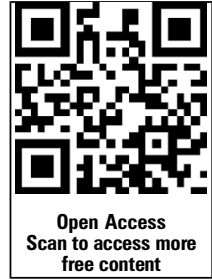

Open Access This is an Open Access article distributed in accordance with the terms of the Creative Commons Attribution (CC BY 4.0) license, which permits others to distribute, remix, adapt and build upon this work, for commercial use, provided the original work is properly cited. See: http:/l creativecommons.org/licenses/by/4.0/

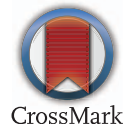

To cite Cole TJ. Arch Dis Child 2015;100:608-609.

Received 2 March 2015

Revised 13 March 2015

Accepted 14 March 2015

Published Online First 15 April 2015

Arch Dis Child 2015;100:608-609.

doi:10.1136/archdischild-2014-307149

\section{REFERENCES}

1 Altman DG, Bland JM. Statistics notes 15. Presentation of numerical data. BMJ 1996;312:572.

2 Lang T, Altman D. Basic statistical reporting for articles published in clinical medical journals: the SAMPL Guidelines. (cited 19 June 2014). http:// www.equator-network.org/wp-content/uploads/2013/ 07/SAMPL-Guidelines-6-27-13.pdf

3 European Association of Science Editors. EASE Guidelines for Authors and Translators of Scientific Articles to be Published in English. 2014 (cited 26 June 2014). http://www.ease.org.uk/sites/default/ files/ease guidelines-june2014-english.pdf

4 Haas DM, Caldwell DM, Kirkpatrick P, et al. Tocolytic therapy for preterm delivery: systematic review and network meta-analysis. BMJ 2012;345:e6226.

5 Cochrane Collaboration. Cochrane Style Guide. 2010 (cited 19 June 2014). 4.1. http://www.cochrane.org/ style-guide/statistical-and-mathematical-presentation

6 American Psychological Association. Publication manual of the American Psychological Association. 6th edn. Washington DC, 2010.

7 Hopkins WG, Batterham AM, Pyne DB, et al. Sports medicine update response. Scand J Med Sci Spor 2011;21:867-8

8 Zhu J, Lin S, Li M, et al. Effect of in vitro culture period on birthweight of singleton newborns. Hum Reprod 2014:29:448-54.

9 Ahmadu BU, Mustapha B, Bappariya JI, et al. The effects of weathering demonstrated by maternal age on low birth weight outcome in babies. Ethiop $J$ Health Sci 2013;23:27-31.

10 Banzi $\mathrm{R}$, Cinquini M, Liberati $A$, et al. Speed of updating online evidence based point of care summaries: prospective cohort analysis. BMJ 2011:343:d5856

11 Cole TJ. Setting the number of decimal places for reporting risk ratios: the rule of four. BMJ 2015;In press.

12 Wainer H. Improving tabular displays, with NAEP tables as examples and inspirations. J Educ Behav Stat 1997;22:1-30

13 Cole TJ. Sympercents: symmetric percentage differences on the $100 \log _{\mathrm{e}}$ scale simplify the presentation of log transformed data. Stat Med 2000;19:3109-25. 